\title{
Thermal environment assessment in selected Polish educational buildings
}

\author{
Luiza Dębska ${ }^{1 *}$, Justyna Krakowiak $^{1}$ \\ ${ }^{1}$ Faculty of Environmental Geomatic and Energy Engineering, Kielce University of Technology, 25-314 Kielce, Poland
}

\begin{abstract}
The paper presents experimental results of a study on indoor thermal environment in selected educational buildings located in the city of Kielce (Poland). The volunteers in the investigated rooms were asked to fill in the anonymous questionnaires containing questions on their thermal sensation, thermal preference and thermal acceptability votes as well as humidity assessment and humidity preference votes. In total, 83 people completed the questionnaires. Simultaneously, the indoor air parameters were measured with a microlimate meter equipped with precision sensors to measure air and globe temperatures, air velocity and relative humidity. The analysis of the obtained results provides information on the subjective assessment of the thermal environment in the considered rooms. It allowed to assess whether the guidelines given in the standard are consistent with the real feeling of comfort of the respondents. Research in the performed scope has shown that the feelings of the respondents and the standard guidelines diverge. It was noticed that that the subjects definitely felt better in the rooms where the temperature was around $22.5^{\circ} \mathrm{C}$. The subjects felt worse at the temperature of $25.3^{\circ} \mathrm{C}$ and the worst of $27.6^{\circ} \mathrm{C}$.
\end{abstract}

\section{Introduction}

People spend most of their lives indoors, due to their work, study or the autumn and winter season. For these several reasons, it is important to create optimal conditions so that you can feel thermal comfort. Thermal comfort is a state directly related to the feeling of temperature in a room - when we are neither too warm nor too cold. The parameters that affect the thermal comfort in rooms are: air and radiant temperatures, physical activity performed by the people, clothing worn by the respondents, relative humidity and etc. Each of these parameters has a different impact on the feeling of comfort. Moreover, in the case of research on thermal comfort the subjective feelings of such people play an important role. The tests are usually done using a sevenpoint scale ranging from -3 to +3 , where -3 is too cold, +3 is too hot. It all consists of the Fanger formula which is used in the ISO 7730 standard to calculate PMV (Predicted Mean Vote) and PPD (Predicted Percentage Dissatisfied) [1], [2].

Thermal comfort tests carried out in educational buildings make it possible to learn about the parameters in which students feel best, which might provide higher learning productivity. Such an example is the research conducted at universities in Spain and Poland, where the internal environment and the climatic zone differed from each other. The most important parameters to be assessed were temperature and relative humidity, where the best temperature was $21.7^{\circ} \mathrm{C}-22.3^{\circ} \mathrm{C}$, and in Spain it was in the range of $23.3^{\circ} \mathrm{C}-24.8^{\circ} \mathrm{C}$. Students definitely accepted the prevailing humidity in both cases, but it was in Poland that the level of satisfaction was higher than the prevailing conditions [3]. As with the Hong Kong study, which also investigated temperature, internal parameters and the associated thermal assessments of students. Thermal comfort was determined for these studies from $21.56^{\circ} \mathrm{C}-26.75^{\circ} \mathrm{C}$ [4]. In France, the air quality in an intelligent building was examined, where the obtained results were satisfactory throughout the measuring period [5]. In India classes with natural ventilation were included in the study, obtaining a temperature of $30.4^{\circ} \mathrm{C}$ and the satisfaction of respondents in $80 \%$ [6]. Majewski et. al. [7] analyzed the indoor environment in two selected intelligent buildings in Poland. The research lasted 1,5 years and covered 117 rooms. During this time, 1369 surveys were carried out, from which the thermal feelings of people were obtained, needed for further analysis. The obtained results were very surprising, as it was found that both these intelligent buildings, despite the enormous contribution and energy savings, did not meet the expectations and thermal preferences of people inside them. The temperature has not always been constant and in some studies the humidity dropped below $25 \%$. From the questionnaires themselves, it was found that only $66.3 \%$ of women and $76.4 \%$ of men were satisfied with the prevailing conditions throughout the entire study [7]. In a school in Slovakia, research was carried out for 5 classes by Vilcekova et. al. [8], who checked the air quality in these five selected rooms and the perceived thermal comfort according to 34 students and 5 teachers. The general survey was satisfactory because the respondents felt good in the rooms tested. The only problem that arose during the tests was too high level of $\mathrm{CO}_{2}$ despite frequent airing of the rooms. Another research on thermal comfort was carried out at the University of Georgia in the United States. The indoor environment was tested in 11 classrooms with a temperature from $21^{\circ} \mathrm{C}$ to $27^{\circ} \mathrm{C}$. The conclusions were that the students did not want any changes in the microclimate conditions in the temperature was around $23.5^{\circ} \mathrm{C}$. And the polls themselves showed that the created indoor environment was accepted by the respondents [9].

\footnotetext{
*Corresponding author: ldebska@tu.kielce.pl
} 
Kuchen and Fisch [10], Hens [11], Moujalled et. al. [12] and Ricciardi and Buratti [13] conducted research in office building in various European countries. Kuchen and Fisch tested 25 building in the winter season. They received 345 measurements, which showed that the temperature was in the range of $21^{\circ} \mathrm{C}-22^{\circ} \mathrm{C}$ [10]. Hens examined 2 office buildings in Belgium, from which he received alarming results. Most of the people completing the questionnaires described their feeling of being unwell [11]. Moujalled et. al. analyzed office spaces in the south of France, where the temperature ranged from $21.1^{\circ} \mathrm{C}$ to $32.9^{\circ} \mathrm{C}$. In the summer period, half of the respondents were dissatisfied with the prevailing conditions, in contrast to the winter period, where almost $90 \%$ people considered the microclimate in office rooms as suitable [12]. In Italy, thermal comfort was tested by Riccardi and Buratti, which used 9 open space offices, conducting 588 surveys, which clearly showed that $60 \%$ of people were disappointed with the prevailing indoor environment [13]. In Great Britain, in 2011, thermal comfort was tested in such a way as to know the thermal sensations of children in comparison to the thermal sensations of adults in one of Southampton primary schools. The most important conclusion was the increased attention to the thermal preferences of school-age children, as the indoor environmental standards that were adopted did not meet their needs. Additionally, it was concluded from the survey that boys prefer cooler temperatures, and girls prefer warmer environments [14]. Another example of this kind of research outside the European Union is Japan. Indraganti et. al. tested 435 people, establishing on this basis that a comfortable temperature was $27.1^{\circ} \mathrm{C}$. The satisfaction level of those surveyed in Japan's office building was very visible [15]. Kwok and Chun also performed thermal sensation studies in Japanese schools, evaluating 74 people. It was concluded from the received questionnaires that naturally ventilated and airconditioned rooms, according to the students' assessment, were in the comfort zone [16]. Hwang et. al. conducted an analysis of seven universities located in Taiwan. The main objective of the research was to compare thermal comfort in rooms with natural ventilation and in air-conditioned rooms, where a total of 944 people were tested. Two temperature ranges were obtained from the research, in which students felt best - from $21.1^{\circ} \mathrm{C}$ to $29.8^{\circ} \mathrm{C}$ and $24.2^{\circ} \mathrm{C}$ to $29.3^{\circ} \mathrm{C}$ [17]. Zhang et. al. at Hunan University in China, they carried out research in two educational buildings. During the research, the questionnaire was completed by 1273 students, obtaining the satisfaction of the respondents with the prevailing indoor microclimate. The results that were obtained were on average $20^{\circ} \mathrm{C}$ and $71 \%$ humidity [18]. In 2013, Dear et. al. analyzed primary and secondary schools in Australia in various climatic zones. The classrooms were air-conditioned and naturally ventilated. A total of 2850 surveys were obtained. The best temperature that corresponded to the students was $22.5^{\circ} \mathrm{C}$. and the range obtained from $19.5^{\circ} \mathrm{C}$ to $26.6^{\circ} \mathrm{C}$. Moreover, it was noticed on this basis that children attending schools in places where the weather is constant, were not able to adjust thermally to the prevailing conditions, while in children who attended schools in places where the weather was changeable, they showed better thermal adaptation to any weather conditions temperature changes [19]. Additionally, Kim and Dear expanded their research into the thermal comfort of Australian students. This time the analysis was based on 4866 surveys, with a cooler temperature preferred. It was also noticed that children who attended schools with air conditioning tolerated it much better than children who did not have such methods of cooling [20]. Guevera et. al. tested 429 people for perceived thermal comfort in classrooms in Ecuador, in three geographic regions Quito, Guayaquil, Tena in December 2017 to the end of January 2018 . The building covered by the study were very similar to each other in terms of building materials and location. It was noticed that in the town of Quito, the respondents felt thermal comfort, in contrast to the people from Guayaquil and Tena where the respondents definitely wanted cooler temperatures, and this was due to the fact that the two places are in a hot and humid climate [22]. Jindal analyzed thermal comfort in children aged 10-18 in classrooms in the period 2015-2016 in India. During this time, 130 people were examined. From the obtained questionnaires, information was obtained that the youth in this school fell comfortable in the range of $15.3^{\circ} \mathrm{C}-33.7^{\circ} \mathrm{C}$. The study showed that children much better and faster adapt to the prevailing room temperature [23].

The following article presents studies from 3 different educational rooms (university and secondary school rooms), with different temperatures, humidity and ventilation methods. First of all, it was checked whether the current temperature is within the range of optimal conditions and whether people arriving in this room are satisfied with their thermal sensations. Such studies are very rare in Central Poland, and in particular in Kielce (except for a few works such as [7], [21], thus the data obtained could be used to more properly set the temperature in the educational rooms and improve the learning performance of the students.

\section{Material and method}

In the study two methods of measuring thermal comfort, direct and indirect, were used. The first one uses questionnaires with questions about the individual thermal sensations of people staying in a given room. The respondents answered among others, questions such as thermal sensations at the moment, feelings of temperature in the room, preferences for possible change of microclimate conditions or air humidity. Other questions related to physical activity and cloths that the respondents had on them. The second method is based on the ISO 7730 standard. According to this standard, the PMV value is calculated, which is the predicted average score in the studied group. In order to perform calculations according to the formula contained in the standard, values such as temperature, humidity and air velocity should be obtained. In this case, measuring meters are used.

A Testo 400 microclimate meter was used, which allows to read data such as air temperature, globe temperature probe, air velocity, relative humidity, light intensity and more. The use of the above two methods makes it possible to learn about the conditions of the microclimate in the room as well as the thermal sensations and preferences for changes of people in such a room. In 
this way, it can be determined whether the ventilation meets the constantly increasing thermal requirements of people. During the tests, the meter was placed in the center of the lecture hall for 15 minutes to the parameters stabilize. After this time the device recorded the necessary and actual data using probes. Figure 1 shows the meter, while Figure 2 an example reading of the parameters changing with time during test.

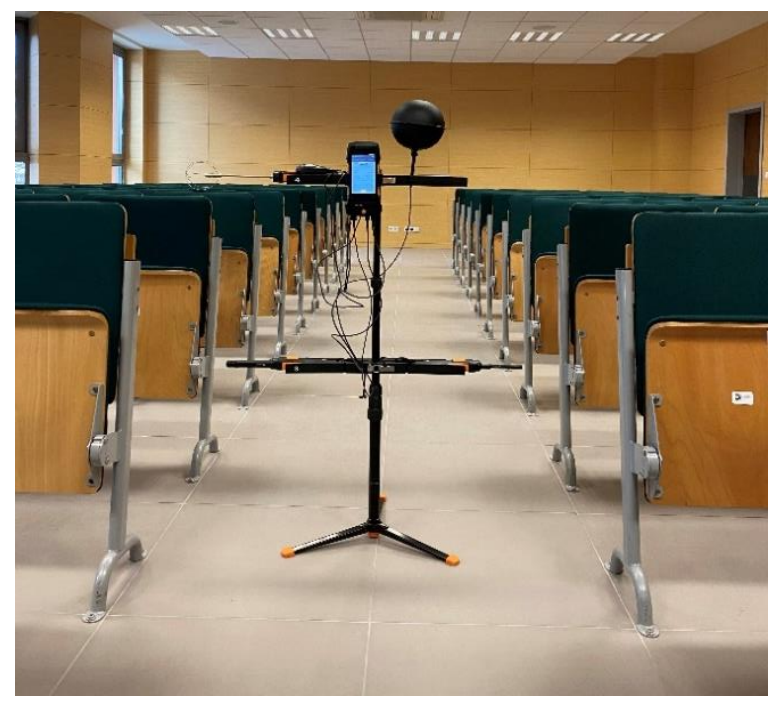

Figure 1. Measuring station

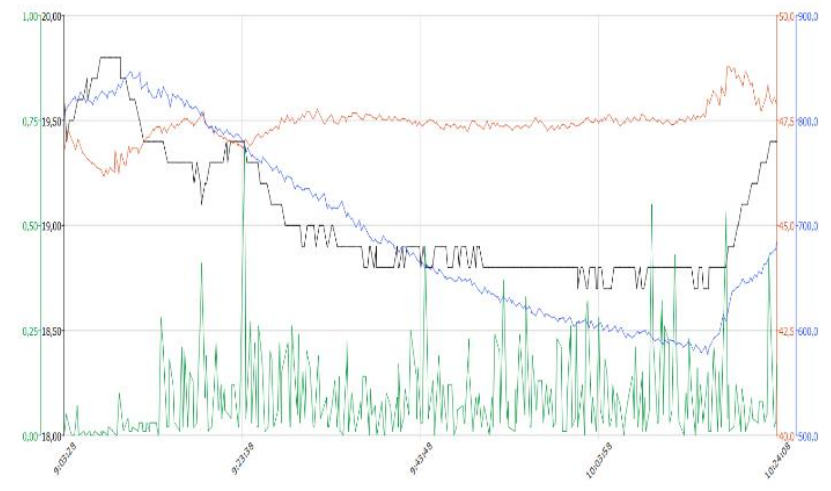

Figure 2. Changes of selected indoor air parameters: air temperature (black line, left axis, ${ }^{\circ} \mathrm{C}$ ), carbon dioxide level (blue line, right axis, ppm), relative humidity (red line, right axis, \%), air velocity (green line, left axis, m/s)

The calculation methodology presented in ISO 7730 standard enabled to determine the values of Predicted Mean Vote (PMV) for each room taking into account measurement results from the high accuracy meter (measurement errors lower then a few percent) and data from the questionnaires regarding clothing insulation. Thus, the comparison between the "real" thermal sensations and the calculated PMV values will be precise.

The study covered three classrooms with different air temperatures and different air exchange methods. At that time, the rooms were neither heated nor cooled. In room 1 the ventilation has a system of work so programmed that it is not possible to change internal parameters. The number of people included in the study was 34 , of which 22 were women and 12 men, in the age range from 19-23 years. In room 2 the ventilation made it possible to change parameters. 10 women and 19 men were examined in this classroom, 29 people in total, aged from 21-24 years. In room 3 was gravitational ventilation - air was exchanged by opening windows and doors. 20 people, including 5 women and 15 men, were surveyed, for the age range of 16-17 years.

\section{Test results of the questionnaire survey in selected rooms}

Table 1 shows the results of the parameters of the internal environment from the testes classrooms. The received results were averaged.

Table 1. Internal environment parameters for rooms 1, 2, 3

\begin{tabular}{|l|c|c|c|}
\hline & Room 1 & Room 2 & Room 3 \\
\hline $\begin{array}{l}\text { Air } \\
\text { temperature } \\
{\left[{ }^{\circ} \mathrm{C}\right]}\end{array}$ & 22.50 & 25.30 & 27.60 \\
\hline $\begin{array}{l}\text { Black ball } \\
\text { temperature } \\
{\left[{ }^{\circ} \mathrm{C}\right]}\end{array}$ & 21.26 & 24.72 & 26.59 \\
\hline $\begin{array}{l}\text { Relative } \\
\text { humidity } \\
{[\%]}\end{array}$ & 52.40 & 52.05 & 50.80 \\
\hline $\begin{array}{l}\text { Average air } \\
\text { velocity } \\
{[\mathrm{m} / \mathrm{s}]}\end{array}$ & 0.21 & 0.30 & 0 \\
\hline
\end{tabular}

From the parameters obtained from three different rooms, it was noticed that the best temperature was in room 1, and the highest was $27.6^{\circ} \mathrm{C}$ in room 3 , which could already indicate a feeling of thermal discomfort as this stage. Relative humidity of approximately $52 \%$ was recorded in rooms 1 and 2. Slightly less, ie. 50\% was recorded in room 3. A huge difference between the rooms can by seen in the average flow of air velocity. In room 1 it was $0.21 \mathrm{~m} / \mathrm{s}$, in room 2 it was $0.30 \mathrm{~m} / \mathrm{s}$, in room 3 the recorded airspeed was $0 \mathrm{~m} / \mathrm{s}$. The following tests described in the article will show and confirm the collected and juxtaposed results of measurements obtained with the use of the meter, which room was in fact the place most adapted to feeling thermal comfort. The clothing thermal isolation (clo) for each study group was about 0.49 . The value was obtained with the help of the same questionnaires from which subjective assessments of participants' warm feelings were obtained. The respondents had to mark items of their clothing while taking measurements with a meter. After analyzing the clothing of each person a duty of 0.49 obtained. Additionally, in order to better analyze thermal sensations, a question was created regarding the physical activity of the subjects. It concerned the issue of rest sitting and a walk that could last at least 10 minutes, so as to obtain a reliable assessment of thermal sensations of the internal environment by the students. Because a sitting or short walk would not have a significant impact on the feelings of the respondents. People who could or did exercise (sports, running) before completing the questionnaire were a false source of information because they would perceive the parameters of the internal environment differently than a person who sat or walked for about 10 minutes. Therefore in the questionnaires 
where the respondents indicated that they had recently performed intense physical effort, they had to be rejected.

Figure 3 below presents a summary of the respondents' responses in which the thermal sensations at a given moment were assessed as TSV (thermal sensation vote).

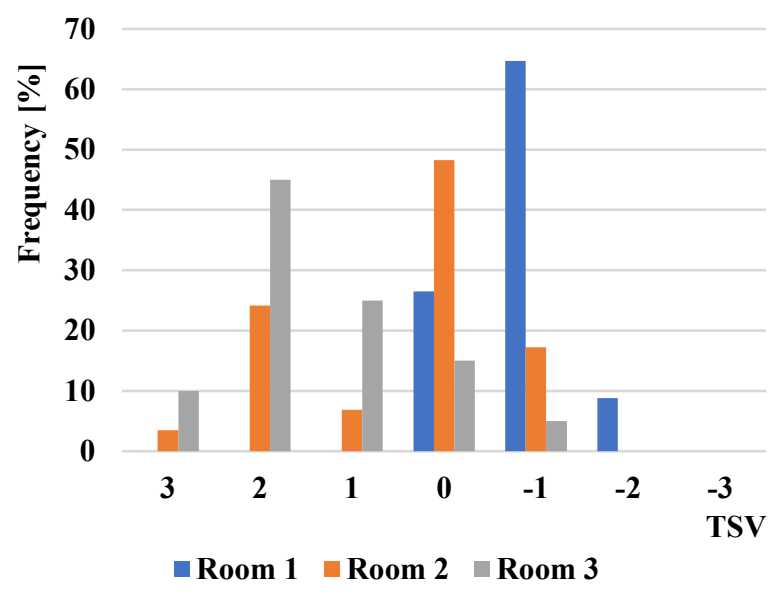

Figure 3. Frequency of answers on thermal sensations: 3 Too hot, 2 - Too warm, 1 - Pleasantly warm, 0 - Comfortable -1 - Pleasantly cool, -2 - Too cool, -3 - Too cold

The thermal feeling as too hot was marked in room 2, and amounted to $3.45 \%$ of the respondents, and in room 3 , constituting $10 \%$ of the respondents. No answer was marked in room $1.45 \%$ of people in room 3 and $24.14 \%$ of people in room 2 think it is too warm in the room. Again in room 1 no answer was picked. Pleasantly warm was marked by $25 \%$ of people from room 3 and $6.90 \%$ respondents from room 2 . In room 1 no answers were recorded. Thermal comfort was experienced by $26.47 \%$, $48.28 \%$ and $15 \%$ of respondents, respectively, where the highest result was obtained in room 2. 64.71\% of people in room 1 described their thermal sensations as pleasantly cool, while in the other two rooms the same state was reported by $17.24 \%$ and $5 \%$ of the surveyed people. Only $8.82 \%$ of people in room 1 said it was too cold. No responses were marked in the remaining rooms. Not a single person indicated that was too cold in the halls. Therefore, it can be concluded that the best thermal sensations, according to the respondents, were recorded in room 1. Figure 4 below shows the temperature acceptability vote (TAV) according to the respondents.

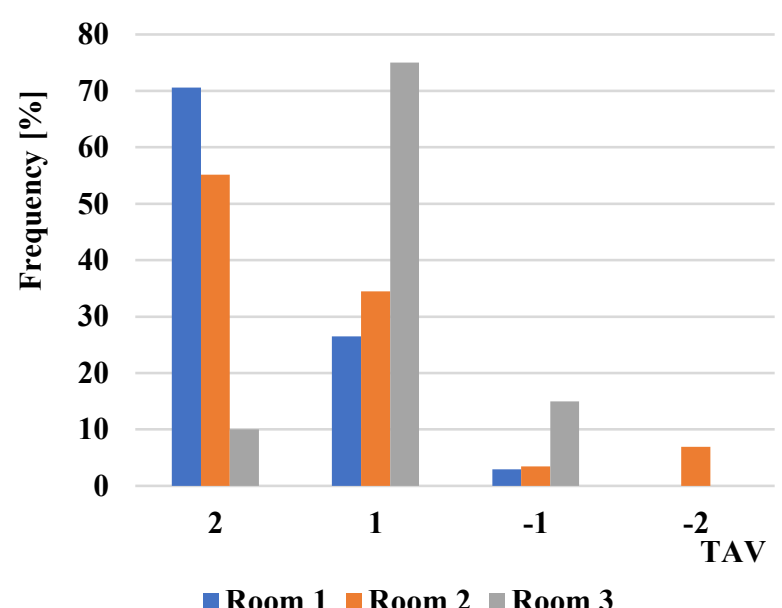

Figure 4. Frequency of answers on temperatures felt: 2 Comfortable, 1 - Acceptable, -1 - Unpleasant, -2 - Definitely unpleasant.

Figure 4 shows that $70.59 \%$ of respondents believe that the temperature in room 1 and is comfortable, as opposed to people in room 3 , where only $10 \%$ of the respondents selected this answer. The temperature was marked as acceptable by as many as $75 \%$ of people in room 3 , while only in room 1 and 2 such an answer was marked by $26.47 \%$ and $34.48 \%$ of the respondents. The conditions were described as unpleasant in turn by $2.94 \%$ of the respondents, then by $3.45 \%$ of the respondents and most in room 3 as much as $15 \%$. The temperature was marked as completely unacceptable only by people from room 2 , thus constituting $6.90 \%$. In figure 5 respondents replied about their thermal preferences.

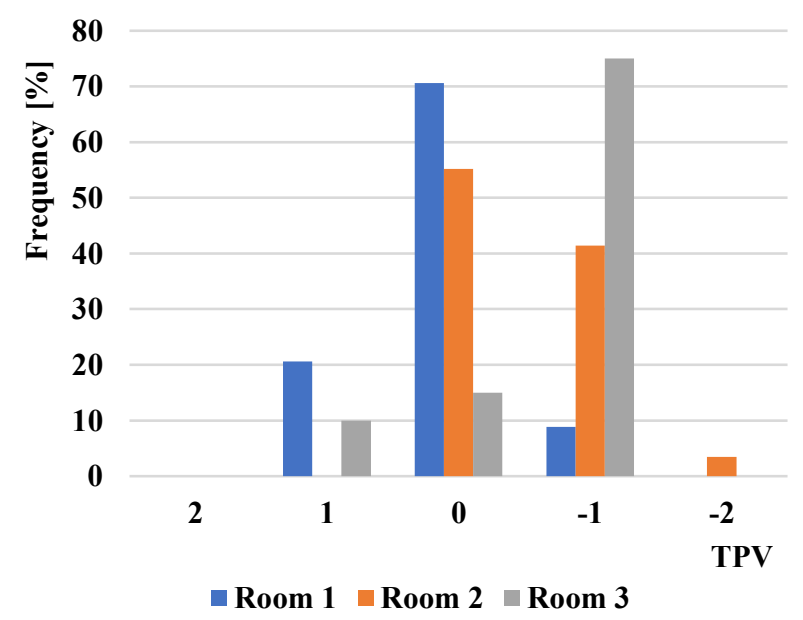

Figure 5. Frequency of answers on thermal preferences vote: 2 - Definitely warmer, 1 - Warmer, 0 - No change, -1 - Cooler, 2 - Definitely cooler.

None of the respondents would decide to make it much warmer in the selected rooms. $20.59 \%$ of people in room 1 and $10 \%$ of people in room 3 would like to change to warmer conditions. As many as $70.79 \%$ of people, 
$55.17 \%$ of people and $15 \%$ of respondents, from each room, would like these people were satisfied with the conditions there. $75 \%$ volunteers would like room 3 to be cooler, $41.38 \%$ from room 2 would also like such a change, and only $8.82 \%$ from room $1.3 .45 \%$ of respondents from room 2 would choose definitely cooler temperature. Figure 6 shows the assessment of air humidity in selected rooms by the respondents.

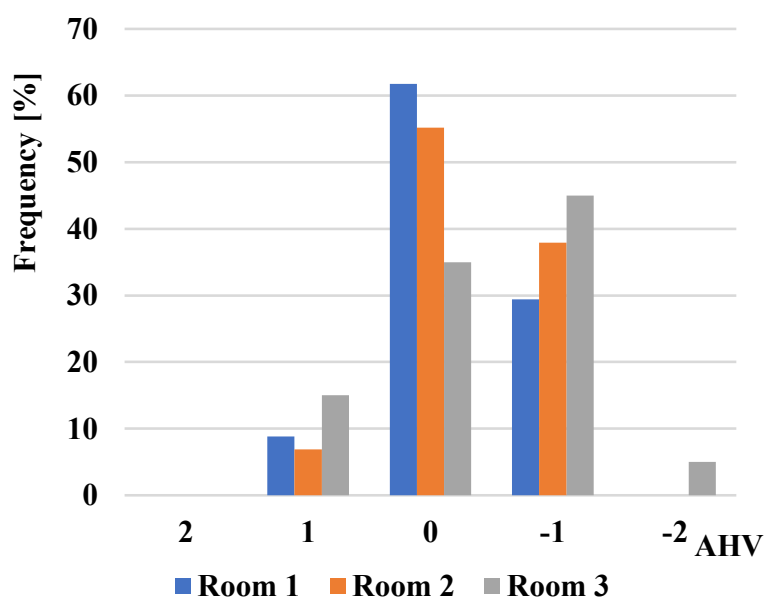

Figure 6. Frequency of answers on assessment of air humidity vote: 2 - Too humid, 1 - Quite humid, 0 - Pleasantly, -1 - Quite dry, $-2-$ Too dry

None of the respondents believed that the selected rooms were too humid. As an answer, quite humid was marked in turn by $8.82 \%$ of the respondents, $6.90 \%$ of the respondents and with the highest number of votes amounting to $15 \%$ from room 3 . Most people satisfied with the prevailing conditions were recorded in room 1 , constituting $61.76 \%$ of the respondents then in room 2 , constituting $55.17 \%$ of the respondents. Only $35 \%$ of satisfaction with air humidity was recorded in room 3 . $29.41 \%$ of respondents from room 1 think that it is quite dry, more people $37.93 \%$ from room 2 and $45 \%$ of respondents from room 3 also have the same opinion about the assessment of air humidity. The subjects from lecture hall 1 and 2 did not feel dry, in contrast to the subjects from room 3 where $5 \%$ of people said it was too dry. On this basis, it was found that the greatest satisfaction in the assessment of humidity in the rooms tested was among people from room 1 and 2, they constituted the greater half of the group. Figure 7 below shows the willingness to change the humidity according to the individual preferences of the respondents.

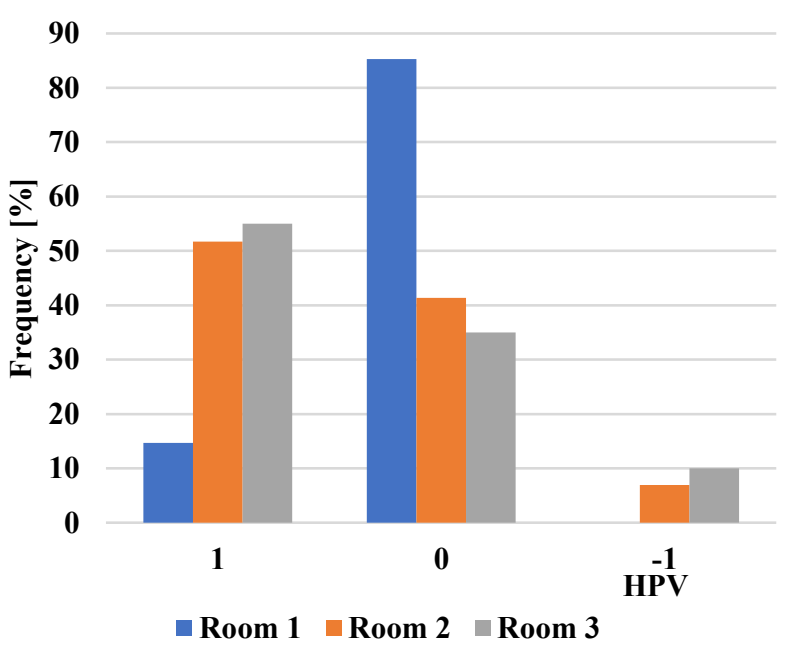

Figure 7. Frequency of answers humidity preferences vote: $1-$ More humid, 0 - No change, -1 - More dry

People from room 2 and 3 would like the air in the room to be more humid accounting for $51.72 \%$ and $55 \%$. People from room 1 were the least of the respondents, representing $14,71 \%$. The air would remain unchanged as much as $85.29 \%$ of the respondents from room 1 , as opposed to room 2 and 3 where the respondents stated themselves in $41.38 \%$ and $35 \%$. No one in room 1 would like the room to be drier. Such willingness was expressed by people from room 2 constituting $6.90 \%$ of the respondents and from room 3 equal to $10 \%$. Figure 8 presents a summary of the calculated PMV values from the obtained questionnaires and using the formula from ISO 7730 .

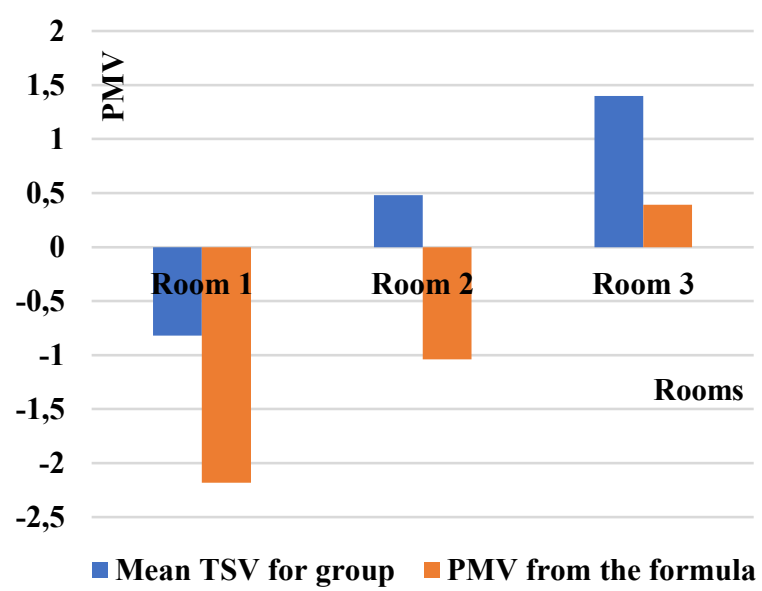

Figure 8. Collective PMV chart from the questionnaires and calculated on the basis of the standard.

Figure 8 sum up the Predicted Mean Vote PMV. On its basis, it can be seen that the obtained results are divergent. There are significant differences between the PMV obtained from the questionnaires and the one calculated on the basis of the formula from the standard. In the room 1 the difference is 1.36 , in room 2 it is 1.52 , and in room 3 is 1.01 . Consequently, the calculation results according to the guidelines indicated in the standard do not seem describe the people's sensations well. 


\section{Conclusions}

The measurement results obtained with the use of the meter, and the results from the questionnaires, definitely coincide, because the study has shown that the best parameters and thermal sensations were assessed by the respondents concerned room 1 . These people thought that the room was pleasant and comfortable for a temperature equal to $22.5^{\circ} \mathrm{C}$. The resulting microclimate was worst assessed in rooms 2 for $25.3^{\circ} \mathrm{C}$ and 3 for $27.6^{\circ} \mathrm{C}$. It is in these rooms that the respondents would like it to be more humid and cool. This may result from the fact that in room 2 the parameters were incorrectly matched to the individual preferences of the respondents and in room 3 it is not possible to replace the used air except by opening windows or doors. The temperature definitely has a huge impact on the human thermal sensations, because too high or too low a temperature can lead to reduced productivity and bad mood. Moreover, the study has shown that the calculation results of PMV might be significantly different from the actual sensations of people expressed by them in the questionnaires.

The present preliminary study will be continued to collect more data on thermal comfort of students in Polish conditions to provide more understanding of the perceptions of people and possibly change the current settings of indoor temperature by building managers to better suit the building occupants.

\section{Acknowledgements}

The project is supported by the program of the Minister of Science and Higher Education under the name: "Regional Initiative of Excellence" in 2019-2022 project number 025 / RID / 2018/19 financing amount PLN 12,000,000.

\section{References}

[1] ASHRAE Standard 55-2017, Thermal Environmental Conditions for Human Occupancy.

[2] Fanger, P.O. (1974). Komfort cieplny. Arkady, Warszawa.

[3] Krawczyk D.A., Gładyszewska-Fiedoruk K., Rodero A., The analysis of microclimate parameters in the classrooms located in different climate zones, Applied Thermal Engineering 113 (2017) 1088-1096. http://dx.doi.org/10.1016/j.applthermaleng.2016 11.089

[4] Fang Z., Zhang S., Cheng Y., Fong A.M.L., Oladokun M.O., Lin Z., Wua H., Field study on adaptive thermal comfort in typical air conditioned classrooms, Building and Environment $\quad 133 \quad$ (2018) 73-82. https://doi.org/10.1016/j.buildenv.2018.02.005

[5] Merabtine A., Maalouf C., Waheed Hawila A.A., Martaj N. Polidori G., Building energy audit, thermal comfort, and IAQ assessment of a school building: A case study. Building and
Environment $145 \quad$ (2018) 62-76, https://doi.org/10.1016/j.buildenv.2018.09.015

[6] Singh M.K., Kumar S., Ooka R., Rijal H.B., Gupta G., Kumar A., Status of thermal comfort in naturally ventilated classrooms during the summer season in the composite climate of India, Building and Environment 128 (2018) 287-304.

https://doi.org/10.1016/j.buildenv.2017.11.031

[7] Majewski, G., Orman, Ł.J., Telejko, M., Radek, N., Pietraszek, J., Dudek, A. (2020). Assessment of thermal comfort in the intelligent buildings in view of providing high quality indoor environment. Energies, 13(8). 1973. 10.3390/en13081973.

[8] Vilcekova S., Meciarova, L.; Burdova, E.K.; Katunska, J.; Kosicanova, D.; Doroudiani, S. Indoor environmental quality of classrooms and occupants' comfort in a special education school in Slovak Republic. Building and Environment 2017, 120, 29-40.

[9] Aghniaey, S.; Lawrence, T.W.; Sharpton, T.N.; Douglass, S.P.; Oliver, T.; Sutter, M. Thermal comfort evaluation in campus classrooms during room temperature adjustment corresponding to demand response.Building and Environment 2019, 148, 488-497.

[10] Kuchen, E.; Fisch, M.N. Spot Monitoring: Thermal comfort evaluation in 25 o_ce buildings in winter.Building and Environment 2009, 44, 839-847.

[11] Hens, H.S.L.C. Thermal comfort in o_ce buildings: Two case studies commented. Building and Environment 2009, 44, 1399-1408.

[12] Moujalled, B.; Cantin, R.; Guarracino, G. Comparison of thermal comfort algorithms in naturally ventilated o_ce buildings. Energy Build. 2008, 40, 2215-2223.

[13] Ricciardi, P.; Buratti, C. Thermal comfort in open plan o_ces in northern Italy: An adaptive approach. Building and Environment 2012, 56, 314-320.

[14] Teli D., James P.A.B., Jentsch M.F., Thermal comfort in naturally ventilated primary school classrooms. Building Research \& Information 42 (2013) 301-316. https://doi.org/10.1080/09613218.2013.773493

[15] Indraganti, M.; Ooka, R.; Rijal, H.B. Thermal comfort in o_ces in summer: Findings from a field study under the 'setsuden' conditions in Tokyo, Japan. Building and Environment 2013, 61, 114-132.

[16] Kwok, A. G., Chun, C., Thermal comfort inJapanese schools. Solar Energy 74 (2003) 245 $252 . \quad$ https://doi.org/10.1016/S0038$\underline{092 \times(03) 00147-6}$ 
[17] Hwang, R.-L.; Lin, T.-P.; Kuo, N.-J., Field experiments on thermal comfort in campus classrooms in Taiwan. Energy and Buildings 38 (2006) 53-62. https://doi.org/10.1016/j.enbuild.2005.05.001

[18] Zhang G., Zheng C., Yang W., Zhang Q., Moschandreas D. J., Thermal Comfort Investigation of Naturally Ventilated Classrooms in a Subtropical Region. Indoor and Built Environment 16 (2007) 148-158. https://doi.org/10.1177/1420326X06076792

[19] Dear de R., Kim J., Candido C., Deuble M., Adaptive thermal comfort in Australian school classrooms. Building Research \& Information 43 (2015) 383-398. https://doi.org/10.1080/09613218.2015.991627

[20] Kim J., Dear de R., Thermal comfort expectations and adaptive behavioural characteristics of primary and secondary school students. Building and Environment 127 (2018) 13-22.

https://doi.org/10.1016/j.buildenv.2017.10.031
[21] Majewski, G., Telejko, M., Orman, Ł.J. Preliminary results of thermal comfort analysis in selected buildings. Proc. of Conf. on Interdisciplinatry Problems in Environmental Protection and Engineering (EKO-DOK), Poland, E3S Web of Conferences, 17, 00056, 2017.

https://doi.org/10.1051/e3sconf/20171700056.

[22] Guevara G.,Soriano G., Mino-Rodriguez I., Thermal comfort in university classrooms: An experimental study in the tropics. Building and Environment 187

(2021) https://doi.org/10.1016/j.buildenv.2020.107430

[23] Jindal A., Thermal comfort study in naturally ventilated school classrooms in composite climate of India. Building and Environment 142 (2018) 34-46. https://doi.org/10.1016/j.buildenv.2018.05.051 